\title{
Be an Advocate for Others, Unless You Are a Man: Backlash Against Gender-Atypical Male Job Candidates
}

Janine Bosak

Dublin City University

Clara Kulich

University of Geneva, Switzerland

Laurie Rudman

Rutgers University, USA

See next page for additional authors

Follow this and additional works at: https://arrow.tudublin.ie/buschmancon

Part of the Business Administration, Management, and Operations Commons, and the Business Analytics Commons

\section{Recommended Citation}

Bosak, J. et al. (2018) Be an Advocate for Others, Unless You Are a Man: Backlash Against GenderAtypical Male Job Candidates, 28th International Congress of Applied Psychology, July 8-13, 2014, Palais des Congrès in Paris, France.

This Article is brought to you for free and open access by the School of Management at ARROW@TU Dublin. It has been accepted for inclusion in Conference Papers by an authorized administrator of ARROW@TU Dublin. For more information, please contact arrow.admin@tudublin.ie, aisling.coyne@tudublin.ie,gerard.connolly@tudublin.ie.

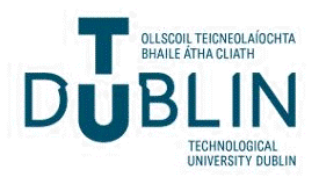




\section{Authors}

Janine Bosak, Clara Kulich, Laurie Rudman, and Mary Kinahan

This article is available at ARROW@TU Dublin: https://arrow.tudublin.ie/buschmancon/49 
Be an Advocate for Others, Unless You Are a Man:

Backlash Against Gender-Atypical Male Job Candidates

\author{
Janine Bosak \\ Dublin City University, Ireland \\ Clara Kulich \\ University of Geneva, Switzerland \\ Laurie Rudman \\ Rutgers University, USA \\ Mary Kinahan \\ Dublin Institute of Technology, Ireland
}

Author Note

The authors thank Margaret Hendrick for her help in collecting the data. Earlier versions of this paper were presented at a Small Group Meeting in Leuven/Belgium, the $17^{\text {th }}$ European Association of Work and Organizational Psychology in Oslo/Norway, and the $28^{\text {th }}$ International Congress of Applied Psychology in Paris/France.

Correspondence concerning this article should be addressed to Janine Bosak, Business

School, Dublin City University, Glasnevin, Dublin 9, Ireland. E-mail: janine.bosak@dcu.ie 


\begin{abstract}
Previous research shows that gender vanguards (individuals who demonstrate genderatypical skills and behavior) suffer backlash in the form of social and economic penalties (Rudman \& Phelan, 2008). This study examined backlash against female and male job applicants who were either gender-atypical or typical. Professionals $(N=149)$ evaluated female or male managerial applicants for internal promotion described in their performance review as showing either self-advocacy or advocacy on behalf of their team. Atypical, other-advocating men were judged to be low on agency and competence and penalized with job dismissal. Serial mediation analysis demonstrated that, compared with other-advocating women, other-advocating men were perceived to lack agency, which contributed to a perceived loss of competence that ultimately led to greater penalties. The implications of these findings for contemporary leadership theories and men's and women's professional success in the workplace are discussed.

Keywords: Gender Discrimination; Backlash; Hiring; Gender Roles; Advocacy
\end{abstract}


Be an Advocate for Others, Unless You Are a Man:

Backlash Against Gender-Atypical Male Job Candidates

Stereotypes play a crucial role in the process of screening job applicants (for reviews, see Barreto, Ryan, \& Schmitt, 2009; Fiske, 1998). In particular, stereotypical beliefs drawn from applicants' social group memberships can bias raters' perceptions and judgments (e.g., Derous, Ryan, \& Serlie, 2015; Fiske, Lin, \& Neuberg, 1999). Thus, understanding when and how stereotypes impact personnel decision-makers is key to ensuring a fair treatment of candidates, as well as an effective recruitment process for organizations (Heilman, 2012).

A large body of research has demonstrated that gender stereotypes influence perceivers and can lead to discrimination in hiring and promotion decisions (e.g., Bosak \& Sczesny, 2011; Heilman, 1983; Heilman \& Okimoto, 2007; Heilman, Wallen, Fuchs, \& Tamkins, 2004; Rudman, Moss-Racusin, Phelan, \& Nauts, 2012; Ryan, Haslam, Morgenroth, Rink, \& Peters, 2016). Reactions have routinely been found to be negative towards self-advocating or otherwise agentic women who face social and economic penalties (termed backlash effects; Rudman, 1998; Rudman \& Fairchild, 2004). Although researchers have traditionally concentrated on backlash against women who disconfirm gender stereotypes (for reviews, see Eagly \& Karau, 2002; Kulik \& Olekalns, 2012; Rudman, Moss-Racusin, Glick, \& Phelan, 2012; Rudman \& Phelan, 2008), men may also be subject to backlash for violating gender stereotypes and norms. Yet, few studies to date have attended to how atypical behaviors create negative expectancy violations for men, generating backlash and negatively affecting men's outcomes (for exceptions, see Heilman \& Wallen, 2010; Moss-Racusin, Phelan, \& Rudman, 2010; Rudman \& Mescher, 2013). The goal of the present study was to address this asymmetry in the literature and to examine backlash against atypical female and male applicants from professional adults. In doing 
so, the study makes three important contributions. First, research on backlash to date has relied predominately on student samples. To overcome this ecological issue, the present study sought to replicate backlash against atypical, self-advocating women using a sample of professionals, many of whom held roles which would typically involve screening applications and making hiring decisions. Second, we sought to extend the scarce research on backlash against atypical men. Third, we uniquely investigated backlash against atypical men who display otheradvocating (vs. self-advocating) behaviors in their work role. Prior research has detected backlash against communal men (Moss-Racusin et al., 2010; Rudman \& Mescher, 2013) who were penalized because they were judged as low in agency. However, certain communal behaviors such as advocating for team members in the workplace might be judged as a strength, rather than a weakness, even for men. Thus, the study addresses a recent call to investigate the scope of negative reactions to atypical men (Moss-Racusin et al., 2010).

\section{Gender Stereotype Violations Promote Backlash}

Social role theory proposes that stereotypical beliefs about men and women stem from observations of the sexes in their typical societal roles, which are believed to require different talents and skills (Eagly, 1987; Eagly, Wood, \& Diekman, 2000; Eagly \& Wood, 2012). Women's more communal roles (e.g., as caretakers) and men's more agentic roles (e.g., as leaders) promote the two fundamental dimensions of gender stereotypes: female communality and male agency, respectively. Further, stereotypical beliefs also dictate what men and women ought to be (prescriptive norms) and ought not to be (proscriptive norms; Prentice \& Carranza, 2002). Gender prescriptions dictate that women should be caring and socially oriented (communal) and that men should be competitive and achievement-oriented (agentic) (Eagly \& Karau, 2002; Eagly \& Steffen, 1984; Fiske, 1998). Gender proscriptions dictate that women 
should not be dominant and men should not be weak (Rudman, Moss-Racusin, Phelan, et al., 2012). As we next describe, gender-atypical behaviors readily translate to perceived violations of gender proscriptions and gender prescriptions (Rudman et al., 2012). Therefore, a critical challenge for female and male applicants in a professional context is their inability to display gender-atypical behaviors that are often required for success without being penalized during the hiring and promotion process.

Backlash against atypical women. Prior research has demonstrated that women often suffer backlash when they appear agentic, self-promoting, or even mildly angry (e.g., Brescoll \& Uhlmann, 2008; Heilman \& Okimoto; 2007; Rudman, 1998; Rudman \& Glick, 1999, 2001). For example, Heilman and Okimoto (2007) found that a successful female manager was liked less and was seen as a less desirable superior compared to a similarly described male counterpart. Moreover, Rudman (1998) found that despite the importance of self-promotion in an interview setting, self-promoting female applicants were judged as lower in social skills and less likely to be hired than male counterparts (see also Rudman \& Glick, 1999; 2001; Rudman et al., 2012). Similarly, only self-advocating women (not men) attempting to negotiate a higher salary suffered backlash (Amanatullah \& Tinsley, 2013). Notably, agentic women suffer penalties not because they lack competence, but because they are seen as unlikable and thus, they are overlooked for hiring and promotions (e.g., Fiske, Bersoff, Borgidia, Deaux, \& Heilman, 1991; Heilman, 2001; Lyness \& Judiesch, 1999; Phelan et al., 2008; Rudman et al., 2012). By contrast, modest women are well liked but judged as insufficiently competent to be hired (e.g., Phelan et al., 2008; Rudman, 1998; Rudman \& Glick, 2001). Thus, professional women in masculine domains are faced with a catch-22: They must act agentically to be seen as competent yet when they do, they risk penalties (Eagly \& Karau, 2002; Rudman \& Phelan, 2008). In contrast, male applicants who 
display identical agentic behaviors as their female counterparts are viewed not only as highly competent but also more likeable and hirable (e.g., Rudman, 1998; Rudman \& Glick, 1999; 2001).

Backlash against atypical men. Investigations of backlash against atypical male workers suggest that they are also subject to penalties for violating gender rules. In addition to observing backlash against modest male applicants (Moss-Racusin et al., 2010; Phelan et al., 2008), researchers found that male family leave requesters received more penalties and fewer rewards than female counterparts due to men's diminished agency (Rudman \& Mescher, 2013). Further, evaluators administered a "wimp penalty" to a man who merely succeeded in a feminine domain (Heilman \& Wallen, 2010). Although promising, research investigating men is embryonic because researchers have focused more on women's challenges. This is likely because stereotypical expectations of agency and ambition for men are congruent with characteristics of successful professionals and leaders (Eagly \& Karau, 2002; Heilman, 1983). Consequently, in male-dominated roles, men, compared to women, face less pressure to overcome stereotypes to succeed. Nonetheless, the scarce number of studies investigating backlash against male workers show that they also suffer penalties for behaving in gender atypical ways (e.g., Heilman \& Wallen, 2010; Moss-Racusin et al., 2010; Rudman \& Mescher, 2013).

\section{Advocacy and the Avoidance of Backlash}

Self-advocating behavior and other-advocating behavior are central to the constructs of agency and communion. The traditional division of responsibilities and roles for men and women was such that men held social roles enhanced by self-advocacy (e.g., powerful boss, authoritative father and protective husband), whereas women occupied the role of advocating for others (e.g., supportive assistant, encouraging wife and mother; Amanatullah \& Tinsley, 2013). Self- 
advocacy is aligned with the male stereotype demanding confidence and self-promotion, whereas other-advocacy is aligned with the female stereotype demanding care-taking (Eagly, 1987). The ample evidence of backlash effects against female professionals who display self-promoting behaviors therefore 'resides primarily in the domain of self-advocacy' (Amanatullah \& Tinsley, 2013 , p. 2). Even when the context demanded self-advocacy, such as when seeking hiring for or promotion to leadership roles (Rudman et al., 2012, Rudman \& Phelan, 2008), or during salary negotiations (Amanatullah \& Tinsley, 2013), women encountered penalties for their genderatypical behavior. By contrast, other-advocating female negotiators avoided social backlash (e.g., Amanatullah \& Tinsley, 2013). Indeed, successful women in masculine domains escaped penalties when merely described as a supportive wife and mother (Heilman \& Okimoto, 2007).

An intriguing question is whether other-advocacy will be viewed as similarly positive for male leaders. On the one hand, growing evidence reviewed above shows that violating gender expectancies elicits backlash effects for men (e.g., Moss-Racusin et al., 2010; Phelan et al., 2008) and that women (not men) are expected to promote the well-being of others over themselves (Rudman \& Mescher, 2013). As a result, we would expect other-advocating men to experience more penalties than other-advocating women. On the other hand, contemporary, 'new genre' leadership theories such as transformational leadership and servant leadership emphasize that leaders should act as mentors to their followers by attending to their needs, putting their subordinates first, and sharing their powers (e.g., Barling, 2016; Judge \& Piccolo, 2004; Koenig, Eagly, Mitchel, \& Ristikari, 2011; Liden, Wayne, Zhao, \& Henderson, 2008). Consequently, within organizations, focus on the development of leaders who prioritize the betterment of their subordinates over their own interests has increased (Boyatzis \& McKee, 2005; George, 2003). Similarly, Bosak and Sczesny (2011) found that business students expected other-oriented 
qualities (e.g., inspirational, encouraging, and cooperative) to increase in importance for managers over time. This perspective suggests that other-advocacy may be judged a desirable behavior for both male and female leaders. The present research will test these competing predictions by examining professionals' reactions to other-advocating men and women in the workplace. Specifically, we assessed professionals' willingness to penalize gender-atypical men. Prior research has also relied on this approach to determine whether atypical men are targeted for hostility and not merely denied rewards (Rudman \& Fairchild, 2004; Rudman \& Mescher, 2013). The findings will yield important implications for understanding the scope of backlash against gender-atypical men.

\section{Hypotheses}

If results are consistent with the backlash literature, atypical female and male applicants for internal promotion to management will experience backlash from professionals. This overarching prediction yields three hypotheses described below (see Hypotheses 2-4), but it is contrasted with an alternative prediction derived from the leadership literature that promotes other-advocacy as a desirable behavior for any leader. The latter prediction reads as follows:

Hypothesis 1. Other-advocating candidates will be rated more positively than selfadvocating candidates, regardless of their gender (i.e., as more likable and hirable, with no differences in agency or competence).

Inherent in the backlash prediction is the assumption that three mechanisms, drawn from prior evidence, underlie the proposed backlash effects: competence, agency, and likeability. Because self-advocating women are perceived as highly competent and agentic (Amanatullah \& Morris, 2010; Bowles, Babcock, \& Lai, 2007; Rudman et al., 2012), we did not expect these ratings to suffer for self-advocating women compared with self-advocating men. Specifically, 
female agency eliminates the perception that men are more competent and better suited for leadership roles than women (Eagly \& Karau, 2002). Instead, we expect that, compared with self-advocating men, self-advocating women who promote their own achievements and reap benefits for themselves will be disliked, which should account for women's compared to men's higher penalties. Therefore:

Hypothesis 2: Self-advocating women will be liked less and penalized more than selfadvocating men and other-advocating women (Amanatullah \& Tinsley, 2013).

Men who deviate from gender norms are often liked, but they suffer backlash in the form of low perceived agency (Moss-Racusin et al., 2010; Rudman \& Mescher, 2013) and competence (e.g., Rudman, 1998; Phelan et al., 2008) because, for men, agentic competence is highly prescribed and violation of this rule undermines their status (Rudman et al., 2012). Therefore, we expect that, compared with other-advocating women, other-advocating men who promote team achievements and reap benefits for the team (rather than themselves) will violate male agency prescriptions.

Hypothesis 3. Other-advocating men will be judged as less agentic and competent and they will be penalized more compared with other-advocating women and self-advocating men.

Agency and competence are often conflated in the gender stereotyping literature, yet conceptually, masculine and feminine competencies are distinguishable. According to social role theory, they stem from gender role segregation (Eagly, 1987). Men are expected to be agentic to succeed in competitive workplaces, whereas women are expected to be communal to succeed as as caregivers. Because expectations of male agency underpin masculine competencies, we ordered our variables in a mediation model to test the following hypothesis: 
Hypothesis 4. A perceived agency deficit in other-advocating men will result in a perceived loss of competence, which will ultimately account for men's higher penalties compared to women's in the other-advocacy condition.

\section{Method}

\section{Participants and Design}

Data were collected online from 156 professionals who participated voluntarily, without compensation. We excluded seven participants who failed the manipulation check by either indicating the wrong gender of the target person ( 2 participants) or no gender at all for the target person (5 participants). Therefore, the final sample consisted of 149 (84 female, 65 male) participants who were predominantly Irish (91.9\%). Of these, $9.4 \%$ were between $18-24$ years of age, $40.9 \%$ between $25-34$ years of age, $34.9 \%$ between $35-44$ years of age, $11.4 \%$ between 45 54 years of age, and $0.7 \%$ between $65-74$ years of age. The majority $(59.7 \%)$ were human resource managers, "people" managers, or organizational psychologists; $40.3 \%$ held other roles including for example, Chief Operating Officer, recruiter, project managers, account managers/accountants, sales manager, support staff/IT, Business Development, Finance, and Marketing. The design of the study was a 2 (Applicant Gender) $\times 2$ (Advocacy: self, other) $\times 2$ (Participant Gender) between-subjects factorial. Although participant gender has rarely influenced backlash results (Rudman, Moss-Racusin, Glick, et al., 2012), there are exceptions, and few studies have investigated professional adults. It was therefore prudent to assess the possibility that men might react more negatively to gender atypical targets than women (Lawson \& Lips, 2014) and to include participant gender in the study design. 


\section{Procedure}

Sampling procedure. One of the authors works in a Human Resources Department of a large international company. She forwarded the study's invitation to work colleagues who then forwarded it to their professional networks. The link to the online survey was also posted to two LinkedIn groups in order to recruit psychologists and Human Resource professionals as participants: the Chartered Institute of Professional Development (CIPD) and HR in Ireland. Participation was voluntary and responses were anonymous.

Study procedure. The online experiment entitled "Perceptions and Decision-Making" was administered by Survey Monkey, which randomly assigned each participant to one of the four experimental conditions. After giving consent, participants reviewed the application materials of either a male or female candidate who was described by their subordinates and colleagues as displaying either self-advocating or other-advocating behaviors. Subsequently all participants completed the same questionnaire. Following debriefing, contact details were provided for those who wanted further information about the study or the results. Study and consent procedures were approved in accordance with the Dublin City University Research Ethics Committee REC Reference: DCUREC/2014/139.

\section{Materials}

Candidate manipulation. All materials were modified from Richardson, Phillips, Rudman, and Glick (2011) for Irish participants, who read a fictitious internal promotion application and curriculum vitae of a candidate applying for a management consultant position in a financial corporation. ${ }^{1}$

Target gender was manipulated via a check box (male or female) on the employment application form and by the candidate's name (either Mary or Michael Murphy). The candidate 
held an MBA and had been employed at the company as a Strategic Growth Associate since 2009, specializing in the areas of sustainable revenue generation and marketing. Past achievements included, "Developed financial model to illustrate sustainable business model and identify alternative revenue streams" and "Designed geographic expansion plan that will be used by the Board to complete growth for next five years." Participants received a memo explaining what skills and competencies were needed to be successful for the position. To afford a strong test of the transformational leadership hypothesis, the description highlighted both communal and agentic requirements. It read as follows:

Mary [Michael] Murphy is being considered for promotion to the Consultant position in our Management Consulting Division. This position requires a good listener who can analyze situations and translate data into meaningful insights and fiscal strategies for clients. We look for candidates with sharp problem-solving skills, a results-oriented track record, and solid leadership experience. In addition, the Consultant will manage several people, which requires mentoring skills and the ability to build team camaraderie. Enclosed you will find excerpts from her annual employee performance review.

Participants then read five quotes from the candidate's annual performance review, two of which described the candidate as either self-advocating or other-advocating. In the male target/ other-advocacy condition, these two statements read as follows: "Michael is determined to further his team. At salary and bonus review time, he appears to be a strong negotiator on behalf of this team and they reap the benefits by always receiving the highest bonus and salary increases," and "Michael is intense. He is a fierce worker who diligently guides his team to success. He wants his team to receive credit where due and is excellent at promoting them. He is happy to share the attention." For the male target/self-advocacy condition, these two statements 
read as follows: "Michael is determined to further his career. At salary and bonus review time, he appears to be a strong negotiator and reaps the benefits by always receiving the highest bonus and salary increase," and "Michael is intense. He is a fierce worker who diligently works for success. He wants to receive credit where due and is excellent at promoting himself. He is happy to be the centre of attention." The female target condition replaced "Michael" with "Mary." With the exception of candidate gender and advocacy, all application materials were identical.

Candidate ratings. Participants responded to all dependent measures on scales ranging from 1 (strongly disagree) to 7 (strongly agree). Three items were averaged to form the liking index $(\alpha=.92)$. Items included, "I personally like this candidate"; "I think that this candidate is generally likeable"; and "I would like to work with this candidate". Four items were averaged to form the competence index $(\alpha=.75)$ : "I think that the candidate is competent"; "I think that the candidate has strong problem-solving skills"; "I think that the candidate is an expert in financial modelling"; and "I think that the candidate has strong analytical skills." Four items assessing agentic personality attributes (confident, ambitious, competitive, and independent) were averaged to form the agency index $(\alpha=.84)$. Two items were averaged to form the penalty index; $r(147)=$ $.69 ; p<.001:$ "How much would you recommend this person be let go next time the company is downsized?" and "How much would you recommend this person be encouraged to work for another organization?"

Manipulation checks. At the end of the survey, participants indicated whether the candidate was male or female. To assess whether our manipulation of self- versus otheradvocacy was successful, participants rated the candidate with regard to two statements on a scale ranging from 1 (strongly disagree) to 7 (strongly agree): "The candidate only thinks of 
herself [himself]" and "The candidate listens to employees and has concern for others (recoded)." Responses were averaged to form the manipulation check index $(\alpha=.79)$.

Demographics. At the end of the survey participants provided the following demographic information: age, gender, nationality, highest level of education, and current occupational role.

\section{Results}

\section{Manipulation Check}

We expected participants to give higher ratings for self- compared to other-advocating candidates on our second manipulation check, and they did. Self-advocating candidates $(M=$ $5.29, S D=1.35)$ received significantly higher scores than other-advocating candidates $(M=3.76$, $S D=1.56), t(147)=6.44, p<.001, d=1.53$.

\section{Backlash Effects}

To test our hypotheses, we submitted the likeability, penalty, agency, and competence, indexes to separate 2 (Target Gender) $\times 2$ (Advocacy: self, other) $\times 2$ (Participant Gender) ANOVAs. The means and standard deviations are shown in Table 1, collapsed by participant gender.

\section{INSERT TABLE 1 HERE}

According to transformational leadership theory, other-advocating men and women should be judged more favorably than self-advocating targets (i.e., higher on likability but lower on penalties) and agency and competence should not be diminished (Hypothesis 1). 
In contrast, according to backlash theory, self-advocating men and women should be judged as similarly agentic and competent because female agency defeats the stereotype that women are less qualified for leadership roles than men. However, self-advocating women should be liked less and penalized more than self-advocating men and other-advocating women for violating gender expectancies (Hypothesis 2). Backlash for atypical men emerges as reduced agency and competence because violating gender expectancies reduces men's status. Therefore, other-advocating men should be judged as less agentic and competent and penalized more than other-advocating women and self-advocating men (Hypothesis 3).

Likeability. Consistent with transformational leadership theory (Hypothesis 1), the main effect for advocacy was significant, $F(1,141)=5.32, p=.02, \eta_{\mathrm{p}}^{2}=.04$, whereby otheradvocating targets $(M=4.87 ; S D=1.34)$ were judged as more likeable than self-advocating targets $(M=4.35 ; S D=1.50)$. Thus, Hypothesis 1 was supported. The main effect for target gender was also significant, $F(1,141)=4.31, p=.04, \eta_{\mathrm{p}}^{2}=.03$, whereby women $(M=4.81 ; S D$ $=1.44)$ were judged as more likeable than men $(M=4.39 ; S D=1.43)$.

Contrary to backlash theory, the expected Target Gender $\times$ Advocacy interaction was not significant, $F(1,141)=1.25, p=.27, \eta_{\mathrm{p}}^{2}=.01$. Inconsistent with the focal backlash prediction for women (Hypothesis 2), the self-advocating female candidate was not liked less than the selfadvocating male candidate, $F(1,141)=0.53, p=.47, d=-0.17$. However, as expected, the selfadvocating woman was liked less than the other-advocating woman, $F(1,141)=5.44, p=.02, d$ $=0.61$. By contrast, the self-advocating and other-advocating male candidates were similarly liked, $F(1,141)=0.77, p=.38, d=.23$. Thus, Hypothesis 2 was partially supported. Finally, because only one other study has revealed greater liking for communal women relative to communal men (Moss-Racusin et al., 2010) we did not predict a similar result, but we found it. 
The other-advocating female candidate was liked more than the other-advocating male candidate, $F(1,141)=4.52, p=.04, d=.59$.

In summary, although the omnibus analysis supported transformational leadership theory's prediction that other-advocating candidates would be liked more than self-advocating candidates, closer inspection revealed that this was true only for female candidates; male candidates were similarly liked regardless of advocacy. Further, greater liking for the woman than the man in the other-advocacy condition is consistent with backlash against atypical men (Moss-Racusin et al., 2010).

Penalties. Results showed the expected Target Gender $\times$ Advocacy interaction, $F(1,141)$ $=5.29, p=.02, \eta_{\mathrm{p}}^{2}=.04$. Consistent with backlash against atypical men, in the other-advocacy condition, the male candidate was penalized more than the female candidate, $F(1,141)=4.84, p$ $=.03, d=.46$. Further, he was penalized more than the self-advocating man, $F(1,141)=3.22, p$ $=.08, d=.35$. Thus, Hypothesis 3 was supported. However, in contrast to the backlash prediction for atypical women, the self-advocating female candidate was not penalized more than the self-advocating male candidate, $F(1,141)=0.97, p=.33, d=.25$. Self-advocating and other-advocating women were similarly penalized, $F(1,141)=2.18, p=.14$, although the means favored the typical woman and the effect size was not trivial, $d=.37$. Thus, Hypothesis 2 was generally not supported.

Agency. Results revealed the predicted Target Gender $\times$ Advocacy interaction, $F(1,141)$ $=7.00, p=.009, \eta_{\mathrm{p}}^{2}=.05$. As expected, self-advocating men and women were judged as similarly agentic, $F(1,141)=1.30, p=.26, d=.25$. That is, female self-advocacy defeated gender stereotypes associating men with agency more than women. However, consistent with backlash against atypical men, in the other-advocacy condition, the male candidate was judged 
as less agentic than the female candidate, $F(1,141)=6.36, p=.013, d=.55$. In addition, men were judged as more agentic when they self-advocated than when they advocated for others, $F(1$, $141)=10.86, p=.001, d=.77$. Thus, Hypothesis 3 was supported. Finally, women in the selfadvocating and other-advocating condition were judged as similarly agentic, $F(1,141)=0.31, p$ $=.58, d=.08$. Thus, other-advocacy did not cost women an agency deficit, as it did for men.

Competence. Results revealed the predicted Target Gender $\times$ Advocacy interaction, $F(1$, $141)=4.15, p=.04, \eta_{\mathrm{p}}^{2}=.03$, but it was qualified by a three-way interaction with participant gender, $F(1,141)=6.99, p=.009, \eta_{\mathrm{p}}{ }^{2}=.05$. Unexpectedly, female participants did not show a significant Target Gender $\times$ Advocacy interaction, $F(1,141)=0.22, p=.64, \eta_{\mathrm{p}}{ }^{2}=.00$. Selfadvocating male and female candidates were judged similarly, as expected $(M=5.36 ; S D=0.74$ and $M=5.44 ; S D=0.71), F(1,141)=0.11, p=.74, d=.11$. However, contradicting backlash against atypical men (Hypothesis 3), women rated the other-advocating male and female candidates as similarly competent $(M=5.43 ; S D=0.71$ and $M=5.36 ; S D=0.81$, respectively), $F(1,141)=0.10, p=.75, d=.09$. In addition, self-advocating and other-advocating male candidates were also judged similarly, $F(1,141)=0.09, p=.77, d=.10$, as were self-advocating and other-advocating female candidates, $F(1,141)=0.14, p=.71, d=.11$. Thus, Hypothesis 3 was not supported for female participants.

In contrast, results for male participants showed the expected significant Target Gender $\times$ Advocacy interaction, $F(1,141)=9.45, p=.003, \eta_{\mathrm{p}}{ }^{2}=.06$. Consistent with the backlash prediction for men (Hypothesis 3), men judged the other-advocating male candidate $(M=4.95$; $S D=1.02)$ lower on competence than the other-advocating female candidate $(M=5.95 ; S D=$ $0.64), F(1,141)=10.29, p=.002, d=1.12$. In addition, men judged the other-advocating male candidate $(M=4.95 ; S D=1.02)$ lower on competence than the self-advocating male candidate 
$(M=5.63 ; S D=0.65), F(1,141)=6.70, p=.01, d=.82$. Thus, Hypothesis 3 was fully supported for male participants. Like women, men also judged the self-advocating male and female candidates to be similarly competent $(M=5.63 ; S D=0.65$ and $M=5.41 ; S D=0.80$, respectively), $F(1,141)=0.77, p=.38, d=.30$. Unlike women, men rated the other-advocating female candidate $(M=5.95 ; S D=0.64)$ somewhat higher on competence than the selfadvocating female candidate $(M=5.41 ; S D=0.80), F(1,141)=3.30, p=.07, d=.72$.

\section{Why is Other-Advocacy Penalized for Men?}

Hypothesis 4 stated that other-advocacy in men would result in perceptions of low agency, leading to a competence deficit, which ultimately results in higher penalties against such men. To test this hypothesis, we conducted a serial multiple mediation analysis (Model 6; Hayes, 2013) using a PROCESS bootstrapping analysis based on 10,000 iterations and accelerated confidence intervals (CI 95\%). Target gender was coded -1 (male) and 1 (female), advocacy was coded -1 (self) and 1 (other), and agency and competence (continuous variables) were centered. We entered the Target Gender $\times$ Advocacy interaction as the predictor, agency and competence as mediators, and penalties as the outcome variable and examined the direct effects, indirect effects, and total effect. We further included the following statistical controls in the analysis: Target Gender, Participant Gender, Advocacy, Target Gender $\times$ Participant Gender, Target Gender $\times$ Participant Gender, Target Gender $\times$ Participant Gender $\times$ Advocacy. Table 2 shows the correlation between the focal variables and Figure 1 shows the results from the bootstrapping analysis.

INSERT TABLE 2 HERE 


\section{INSERT FIGURE 1 HERE}

As shown in Figure 1, the Target Gender $\times$ Advocacy interaction predicted agency, $b=$ $0.18, S E=0.70, t(141)=2.65, p=.009$ (Path A). Further, consistent with our expectations, agency predicted competence, $\mathrm{B}=0.32, S E=0.74, t(140)=4.39, p<.001$ (Path B), which in turn predicted penalties, $\mathrm{B}=-0.39, S E=0.12, t(139)=-3.32, p=.001$ (Path C). Most importantly, the sequential effect of Target Gender $\times$ Advocacy on penalties through agency and competence was fully established as predicted. These findings are consistent with our Hypothesis 4 in that other-advocating men are penalized more than female counterparts because of an agency deficit that subsequently lowers their competence, which results in penalties (see Indirect 1 in Figure 1). The other two indirect effects, the indirect effect of Target Gender $\times$ Advocacy interaction on penalties via agency (see Indirect 2 in Figure 1) and the indirect effect of the Target Gender $\times$ Advocacy interaction on penalties via competence (see Indirect 3 in Figure 1), were not significant.

\section{Discussion}

Backlash against atypical individuals robs people of their ability to stand out as gender vanguards and, as a form of discrimination, it also compromises an organization's ability to hire and promote the best applicants (Heilman, 2012). To examine its scope, the present study investigated backlash against atypical female and male applicants with a sample of professionals.

The findings provided support for backlash against atypical men and no support for transformational leadership theory's prediction that other-advocacy would be viewed more favorably than self-advocacy. First, both genders penalized the other-advocating male candidate 
more than the other-advocating woman $(d=0.46)$, and viewed him as less agentic $(d=0.55)$. They also viewed him as less agentic $(d=0.77)$ and penalized him more $(d=0.35)$ than a selfadvocating man. Second, both genders liked the other-advocating woman more so than the otheradvocating man $(d=.59)$. Third, compared with the other-advocating male candidate, men gave higher competence ratings to an other-advocating woman $(d=1.12)$ and a self-advocating man $(d=0.82)$. Thus, men were more biased than women when judging the competence of otheradvocating men. Nonetheless, both genders penalized the other-advocating male candidate and viewed him as less agentic than a female counterpart.

Unexpectedly, there was scant support for backlash against a self-advocating female candidate. The only evidence for Hypothesis 2 was that she was liked less $(d=-0.61)$ and penalized somewhat more $(d=.37)$ than the other-advocating woman, although the latter result was not statistically significant. Further, while female self-advocacy protected women against agency and competence deficits compared with male candidates, it did not yield improved ratings relative to the other-advocating woman. In fact, men tended to judge the other-advocating female candidate as more competent than the self-advocating woman $(d=.72)$. Thus, otheradvocacy for women was generally beneficial, whereas it was costly for men, which is more consistent with backlash against atypical men (Hypothesis 3) than with transformational leadership theory (Hypothesis 1).

\section{Theoretical Contributions}

The present study yields three key contributions. First, backlash against atypical men was extended to men who advocate for others. This finding is important because transformational leaders are largely advocates for their team members and subordinates (e.g., Judge \& Piccolo, 2004; Koenig, et al., 2011). Therefore, it was possible that other-advocacy would be viewed 
favorably, regardless of applicant gender. Instead, compared with an other-advocating female applicant, the identically described male applicant was judged as less agentic and recommended for more organizational penalties. Moreover, male professionals judged him as less competent than either an other-advocating woman or a self-advocating man.

Second, the present study contributes to the scarce literature on backlash against atypical men by investigating the underlying mechanisms for greater penalties received by otheradvocating men compared to other-advocating women. Results were consistent with the hypothesis that penalizing other-advocating men stems from an agency deficit that leads to reduced competence ratings. Although prior research identified both agency and competence deficits for atypical men (Moss-Racusin et al., 2010; Phelan et al., 2008; Rudman \& Mescher, 2013), the present research uniquely tested their simultaneous role in penalizing atypical men. Thus, our findings address the call to "investigate the underpinnings of negative reactions to atypical men" (Moss-Racusin et al., 2010, p. 147) by explaining how gender rules reinforce men's adherence to masculine prescriptions and prevent social change.

Third, contradicting the extant backlash literature (for reviews, see Eagly \& Karau, 2002; Kulik \& Olekalns, 2012; Rudman et al., 2012; Rudman \& Phelan, 2008) we did not find evidence of backlash against atypical, self-advocating women on the part of working professionals. Rather, responses to self-advocating women showed the same pattern as responses to self-advocating men. Although the self-advocating woman suffered in comparison to otheradvocating woman (i.e., she was liked less, penalized more, and judged by men to be less competent), backlash effects typically emerge as gendered double standards, which were not observed. Given considerable evidence of backlash against self-advocating women, this result was surprising. Although speculative, we offer two explanations. First, backlash against self- 
promoting women is usually investigated with video or audio stimuli, or interactions with confederates (e.g., Amanatullah \& Tinsley, 2013; Rudman, 1998; Rudman \& Glick, 2001; Rudman et al., 2012), whereas we manipulated gender typicality using written materials. People may react more strongly to atypical women when their agency is witnessed. The few field experiments in which job applications were sent to companies also did not show evidence of backlash against agentic women (Carlsson et al., 2014; Weichselbaumer, 2004). Second, professionals experienced in acting as decision makers when screening applications might be more conscious of potential gender bias and thus seek to counteract it, particularly HR professionals and psychologists who are trained in anti-discrimination practices and aware of pressures to treat women equally (Paustian-Underdahl \& Walker, 2015).

Nonetheless, even professionals showed consistent bias against the other-advocating male applicant, suggesting that efforts to increase awareness of gender bias need to expand to incorporate men who disconfirm gender rules. This is a critical need, not only to prevent discrimination against atypical men, but also to promote equality for women. Because more men than women occupy leadership roles in the workplace, recruiting men to serve as ambassadors for women (i.e., as their advocates) is vital for gender progress.

Traditionally, in work settings, men are expected to behave in an assertive and competitive manner (e.g., to outdo rivals; Tannen, 1994), and masculine ideals include ambition and being oriented toward one's career (Prentice \& Carranza, 2002). Thus, atypical men suffer backlash because they violate expectations for agency that are strongly prescribed for men (Rudman et al., 2012). Nonetheless, contemporary leadership theory calls for leaders to act as advocates and mentors in the workplace (e.g., Judge \& Piccolo, 2004; Koenig et al., 2011; Liden et al. 2008). From that perspective, advocacy on behalf of team members should have been 
judged as a strength, rather than a weakness, even for men. Instead, our findings suggest that training designed to encourage participants to practice transformational leadership might actually yield negative consequences for men.

Why? Perhaps other-advocacy represents a characteristic which leaders ought to have in the future (Bosak \& Sczesny, 2011), but which has yet to be incorporated into people's beliefs about contemporary men. Following social role theory (Eagly et al., 2000), over time, if people routinely observe other-advocacy in successful male managers, it should promote favorability toward supportive male leaders (Kashima, Woolcock, \& Kashima, 2000). In the present study, championing others was more beneficial for female than male candidates. Therefore, the present study expands the scope of backlash against atypical men (Moss-Racusin et al., 2010) to including advocating for others in a critical context: when applicants are judged by experienced professionals making personnel decisions.

\section{Limitations and Suggestions for Future Research}

Although the present research provided clear evidence of backlash against otheradvocating male applicants, future research should replicate our findings to increase their generalizability. We further encourage researchers to use real-world decision makers including

recruiters and HR managers. The present study used professional adults and thus tested the external validity of backlash findings that have primarily relied on student samples; however, not all study participants were actually involved in hiring decisions in their jobs. In addition, determining the conditions under which male other-advocacy might be beneficial rather than detrimental remains an important empirical question. For example, advocating for others may be viewed favorably on the part of male leaders in more feminine domains (e.g., education and social service) that require the type of communal skills that are aligned with other-advocacy 
(Eagly \& Karau, 2002). The gender composition of the job influences people's perceptions of leadership ability (Ko, Kotrba, \& Roebuck, 2015). Because we used a male-dominated occupation (financial manager), people likely viewed it in masculine terms. On the one hand, this rendered an other-advocating man incongruent with respect to his gender as well as his occupation. On the other hand, a man might have more allowance to behave communally because the prestige of his gender and role protects his masculinity (Shen-Miller \& Smiler, 2015). Further, contemporary leadership theories emphasize the need for managers to act communally, which is why reactions to other-advocating men could have been quite positive. Future research should include assessments of the qualities necessary to succeed in the leadership role as a moderator of reactions to gender-atypical men. In addition, because women's reactions to atypical women are dependent on perceptions of her similarity to the self (Lawson \& Lips, 2014; Parks-Stamm, Heilman, \& Hearns, 2008), at least male participants high on communality might be less likely to penalize other-advocating male managers.

Finally, research is needed to study men's fear of backlash, which might prevent them from engaging in other-advocating behaviors in the workplace, just as fear of backlash for selfpromotion inhibits women from self-advocacy (Moss-Racusin \& Rudman, 2010). Prior research has shown that atypical men and women are aware of backlash and strive to avoid it (Amanatullah \& Morris, 2010; Rudman \& Fairchild, 2004; Moss-Racusin \& Rudman, 2010). We thus encourage research on gender and management to further advance our knowledge of modes of discrimination in the workplace (for overviews, see Broadbridge \& Hearn, 2008; Broadbridge \& Simpson, 2011) including the study of backlash effects, and to do so for both genders women and men

\section{Conclusion}


The present findings contribute to the growing literature on backlash against atypical men by revealing the penalties applied by professionals to other-advocating male applicants. Our results provide external validation to the laboratory studies with university student samples that have shown that atypical men are subject to backlash in the workplace. When men embody desired leadership behaviors by advocating for others, they risk recommendations for dismissal as a result of reduced agency and competence. Therefore, it seems imperative that HR professionals and decision-makers attend to gender bias and to curb backlash not only against atypical women, but also against atypical men in the workplace. 


\section{References}

Amanatullah, E. T., \& Morris, M. W. (2010). Negotiating gender roles: Gender differences in assertive negotiating are mediated by women's fear of backlash and attenuated when negotiating on behalf of others. Journal of Personality and Social Psychology, 98, 256-267. doi: 10.1037/a0017094

Amanatullah, E. T., \& Tinsley, C. H. (2013). Punishing female negotiators for asserting too much ... or not enough: Exploring why advocacy moderates backlash against assertive female negotiators. Organizational Behavior and Human Decision Processes, 120, 110122. doi: 10.1016/j.obhdp.2012.03.006

Barling, J. (2016). The science of leadership: Lessons from research for organizational leaders. NY: Oxford University Press.

Barreto, M., Ryan, M. K., \& Schmitt, M. (Eds) (2009). The glass ceiling in the 21 st Century: Understanding barriers to gender equality. APA Division 35 Book Series.

Bosak, J., \& Sczesny, S. (2011). Gender Bias in Leader Selection? Evidence from a Hiring Simulation Study. Sex Roles, 65, 3-4, 234-242. doi: 10.1007/s11199-011-0012-7

Bowles, H. R., Babcock, L., \& Lai, L. 2007. Social incentives for gender differences in the propensity to initiate negotiations: Sometimes it does hurt to ask. Organizational Behavior and Human Decision Processes, 103, 84-103. doi:

10.1016/j.obhdp.2006.09.001

Boyatzis, R., \& McKee, A. (2005). Resonant Leadership. Harvard Business School Press: Boston. 
Brescoll, V. L., \& Uhlmann, E. L. (2008). Can an angry woman get ahead? Status conferral, gender, and expression of emotion in the workplace. Psychological Science, 19, 268275. doi: 10.1111/j.1467-9280.2008.02079.x

Broadbridge, A. \& Hearn, J. (2008). Gender and management: New directions in research and continuing patters in practice. British Journal of Management, 19, 38-48. doi: 10.1111/j.1467-8551.2008.00570.x

Broadbridge, A. \& Simpson, (2008). 25 years on: Reflecting on the past and looking to the future in gender and management research. British Journal of Management, 22, 470-483. Doi: 10.1111/j.1467-8551.2011.00758.x

Carlsson, R., Agerström, J., Björklund, F., Carlsson, M., Rooth, D. (2014). Testing for Backlash in Hiring: A Field Experiment on Agency, Communion, and Gender. Journal of Personnel Psychology, 13, 204-214. doi: 10.1027/1866-5888/a000126

Derous, E., Ryan A. M., \& Serlie, A. W. (2015) Double Jeopardy Upon Resumé Screening: When Achmed Is Less Employable Than Aïsha. Personnel Psychology, 68, 659-696. doi: $10.1111 /$ peps. 12078

Eagly, A. H. (1987). Sex differences in social behavior. A social-role interpretation. Hillsdale, NJ: Lawrence Erlbaum.

Eagly, A. H., \& Karau, S. J. (2002). Role congruity theory of prejudice toward female leaders. Psychological Review, 109, 573-598. doi: 10.1037//0033-295X.109.3.573

Eagly, A. H., \& Steffen, V. J. (1984). Gender stereotypes stem from the distribution of women and men into social roles. Journal of Personality and Social Psychology, 46, b735-754. doi: $10.1037 / 0022-3514.46 .4 .735$ 
Eagly, A. H., \& Wood, W. (2012). Biosocial construction of sex differences and similarities in behavior. In J. M. Olson \& M. P. Zanna, (Eds.), Advances in Experimental Social Psychology, Vol. 46, (pp.55-123). Burlington: Academic Press.

Eagly, A. H., Wood, W., \& Diekman, A. B. (2000). Social role theory of sex differences and similarities: A current appraisal. In T. Eckes \& H. M. Trautner (Eds.), The developmental social psychology of gender (pp. 123-174). Mahwah, NJ: Erlbaum.

Fiske, S. T. (1998). Stereotyping, prejudice, and discrimination. In D. T. Gilbert, S. T. Fiske \& G. Lindzey (Eds), The handbook of social psychology, 4th ed (pp. 357-411). New York: McGraw-Hill.

Fiske, S. T., Bersoff, D. N., Borgida, E., Deaux, K., \& Heilman, M. (1991). Social science on trial: Use of sex stereotyping research in Price Waterhouse v. Hopkins. American Psychologist, 46, 1049-1060. doi: 10.1037/0003-066X.46.10.1049

Fiske, S. T., Lin, M., \& Neuberg, S. L. (1999). The continuum model: Ten years later. In S. Chaiken \& Y. Trope (Eds.), Dual-process theories in social psychology (pp. 231254). New York, NY: Guilford Press.

George, B. (2003). Authentic leadership: Rediscovering the secrets to creating lasting value. San Francisco, CA: Jossey-Bass.

Heilman, M. E. (1983). Sex bias in work settings: The lack of fit model. In B. M. Staw \& L. L. Cummings (Eds.), Research in Organizational Behavior (Vol. 5, pp. 269-298). Greenwich, CT: JAI Press.

Heilman, M. E. (2001). Description and prescription: How gender stereotypes prevent women's ascent up the organizational ladder. Journal of Social Issues, 57, 657-674. doi: 10.1111/0022-4537.00234 
Heilman, M. E. (2012). Gender stereotypes and workplace bias. Research in Organizational Behavior, 32, 113-135. doi: 10.1016/j.riob.2012.11.003

Heilman, M. E., \& Okimoto, T. G. (2007). Why are women penalized for success at male tasks?: The implied communality deficit. Journal of Applied Psychology, 92, 81-92. doi: $10.1037 / 0021-9010.92 .1 .81$

Heilman, M. E., \& Wallen, A. S. (2010). Wimpy and undeserving of respect: Penalties for men's gender-inconsistent success. Journal of Experimental Social Psychology, 46, 664-667. doi: 10.1016/j.jesp.2010.01.008

Heilman, M. E., Wallen, A. S., Fuchs, D., \& Tamkins, M. M. (2004). Penalties for success: Reactions to women who succeed at male gender-typed tasks. Journal of Applied Psychology, 89, 416-427. doi: 10.1037/0021-9010.89.3.416

Judge, T. A., \& Piccolo, R. (2004). Transformational and transactional leadership: A meta-analytic test of their relative validity. Journal of Applied Psychology, 89, 755-768. doi: $10.1037 / 0021-9010.89 .5 .755$

Ko, I., Kotrba, L., \& Roebuck, A. (2015). Leaders as males? The role of industry gender composition. Sex Roles, 72, 294-307. doi:10.1007/s11199-015-0462-4

Koenig, A. M., Eagly, A. H., Mitchell, A. A., \& Ristikari, T. (2011). Are leader stereotypes masculine? A meta-analysis of three research paradigms. Psychological Bulletin, 137, $616-642$.

Kulik, C. T., \& Olekalns, M. (2012). Negotiating the gender divide: Lessons from the negotiation and organisational behaviour literatures. Journal of Management, 38, 1387-1415. doi: 10.1177/0149206311431307 
Liden, R. C., Wayne, S. J., Zhao, H., \& Henderson, D. (2008). Servant leadership:

Development of a measure and multi-level assessment. The Leadership Quarterly, 19, 161-177. doi: 10.1016/j.leaqua.2008.01.006

Lawson, K., \& Lips, H. M. (2014). The role of self-perceived agency and job attainability in women's impressions of successful women in masculine occupations. Journal of Applied Social Psychology, 44, 433-441. doi: 10.1111/jasp.12236

Lyness, K. S., \& Judiesch, M. K. (1999). Are women more likely to be hired or promoted into management positions? Journal of Vocational Behavior, 54, 158-173. doi: 10.1006/jvbe. 1998.1646

Moss-Racusin, C. A., Phelan, J. E., \& Rudman, L. A. (2010). When men break gender rules: Status incongruity and backlash against model men. Psychology of Men \& Masculinity, 11, 140-151. doi: 10.1037/a0018093

Moss-Racusin, C. A., \& Rudman, L. A. (2010). Disruptions in women's self-promotion: The backlash avoidance model. Psychology of Women Quarterly, 34, 186-202. doi: 10.1111/j.1471-6402.2010.01561.x

Parks-Stamm, E. J., Heilman, M. E., \& Hearns, K. A. (2008). Motivated to Penalize: Women's Strategic Rejection of Successful Women. Personality and Social Bulletin, 34, 237-247. doi: 10.1177/0146167207310027

Paustian-Underdahl, S. C., \& Walker, L. S., (in press). Revisiting the beauty is beastly effect: Examining when and why sex and attractiveness impact hiring judgments. The International Journal of Human Resource Management. 
Phelan, J. E., Moss-Racusin, C. A., \& Rudman, L. A. (2008). Competent yet out in the cold: Shifting Criteria for hiring reflect backlash toward agentic women. Psychology of Women Quarterly, 32, 406-413. doi: 10.1111/j.1471-6402.2008.00454.x

Prentice, D. A., \& Carranza, E. (2002). What women and men should be, shouldn't be, are allowed to be, and don't have to be: The contents of prescriptive gender stereotypes. Psychology of Women Quarterly, 26, 269-281. doi: 10.1111/1471-6402.t01-1-00066

Reskin, B.F., \& Roos, P.A., (1990). Job queues, gender queues: Explaining women's inroads into male occupations. Philadelphia: Temple University Press.

Richardson, E., Phillips, K. W., Rudman, L., \& Glick, P. (2011). Double jeopardy or greater latitude?: Do Black Women escape backlash for dominance displays. Working paper, Columbia Business School.

Rudman, L. (1998). Self-promotion as a risk factor for women: The costs and benefits of counterstereotypical impression management. Journal of Personality and Social Psychology, 74, 629-645. doi: 10.1037/0022-3514.74.3.629

Rudman, L. A. \& Fairchild, K. (2004). Reactions to counterstereotypic behavior: The role of backlash in cultural stereotype maintenance. Journal of Personality and Social Psychology, 87, 157-176. doi: 10.1037/0022-3514.87.2.157

Rudman, L. A., \& Glick, P. (1999). Feminized management and backlash toward agentic women: The hidden costs to women of a kinder, gentler image of middle-managers. Journal of Personality and Social Psychology, 77, 1004-1010. doi: 10.1037/00223514.77.5.1004

Rudman, L. A., \& Glick, P. (2001). Prescriptive gender stereotypes and backlash toward agentic women. Journal of Social Issues, 57, 743-762. doi: 10.1111/0022-4537.00239 
Rudman, L. A., \& Mescher, K., \& Moss-Racusin, C. A. (2013). Reactions to gender egalitarian men: Feminization due to stigma-by-association. Group Processes and Intergroup Relations, 16, 572-599. doi: 10.1177/1368430212461160

Rudman, L. A., Moss-Racusin, C. A., Glick, P., \& Phelan, J. E. (2012). Reactions to vanguards: Advances in backlash theory. In Devine, P. G., \& Plant, E. A. (Eds.), Advances in Experimental Social Psychology, 45, 167-227.

Rudman, L. A., Moss-Racusin, C. A., Phelan, J. E., \& Nauts, S. (2012). Status incongruity and backlash effects: Defending the gender hierarchy motivates prejudice toward female leaders. Journal of Experimental Social Psychology. 48, 165-179. doi: 10.1016/j.jesp.2011.10.008

Rudman, L. A., \& Phelan, J. E. (2008). Backlash effects for disconfirming gender stereotypes in organizations. In A. P. Brief \& B. M. Straw (Eds.), Research in organizational behaviour, (pp. 61-79). New York: Elsevier.

Ryan, M. K., Haslam, S. A., Morgenroth, T., Rink, F., Stoker, J., \& Peters, K. (2016). Getting on top of the glass cliff: Reviewing a decade of evidence, explanations, and impact. Leadership Quarterly. doi:10.1016/j.leaqua.2015.10.008

Shen-Miller, D., \& Smiler, A. P. (2015). Men in female-dominated vocations: A rationale for academic study and introduction to the special issue. Sex Roles, 72, 269-276. doi:10.1007/s 11199-015-0471-3

Tannen, D. (1994). Talking from 9 to 5: Women and men in the workplace: Language, sex, and power. New York: Morrow. 
Weichselbaumer, D. (2004). Is it sex or personality? The impact of sex stereotypes on discrimination in applicant selection. Eastern Economic Journal, 30, 159-186. doi: $10.2307 / 40326127$ 
Table 1

Means (Standard Deviations) on Likeability, Penalties, Agency and Competence by Advocacy and Target Gender

\begin{tabular}{|c|c|c|c|c|c|}
\hline \multirow{3}{*}{ Advocacy } & \multicolumn{5}{|l|}{$\underline{\text { Target }}$} \\
\hline & \multirow[t]{2}{*}{$\underline{\text { Gender }}$} & \multicolumn{4}{|c|}{ Dependent Variable } \\
\hline & & Likeability & Penalties & Agency & Competence \\
\hline \multirow[t]{3}{*}{ Self } & Male & $4.22_{\mathrm{a}}(1.44)$ & $2.12_{\mathrm{a}} \quad(0.98)$ & $6.40 \mathrm{a}(0.57)$ & $5.50_{a}(0.70)$ \\
\hline & Female & $4.47 \mathrm{a}(1.55)$ & $2.38_{\mathrm{a}} \quad(1.08)$ & $6.18 \mathrm{a}(1.07)$ & $5.43_{\mathrm{a}}(0.74)$ \\
\hline & $d$ & -0.17 & -0.25 & 0.25 & 0.10 \\
\hline \multirow[t]{3}{*}{ Other } & Male & $4.55_{\mathrm{a}}(1.43)$ & $2.51_{\mathrm{a}}(1.21)$ & $5.83_{\mathrm{a}}(0.88)$ & $5.25_{\mathrm{a}}(0.86)$ \\
\hline & Female & $5.31_{b}(1.09)$ & $2.00_{b}(0.98)$ & $6.25_{b}(0.55)$ & $5.56_{b}(0.80)$ \\
\hline & $d$ & -0.59 & 0.46 & -0.55 & -0.37 \\
\hline
\end{tabular}

Note. Means for male and female candidates within advocacy not sharing a subscript differ significantly at the $p<.05$ level. Positive effect sizes (Cohen's $d$ ) reflect rating men higher than women. Cell $n s$ ranged from 29 to 42. 
Table 2

Descriptive Statistics and Correlations Among Focal Variables

\begin{tabular}{lllllll}
\hline Variables & $\mathrm{M}$ & $\mathrm{SD}$ & 1 & 2 & 3 & 4 \\
\hline Likeability & 4.59 & 1.45 & & & \\
Penalties & 2.28 & 1.08 & $-.23^{* *}$ & & \\
Agency & 6.16 & 0.84 & .00 & $-.25^{* *}$ & \\
Competence & 5.42 & 0.78 & .16 & $-.35^{* *}$ & $.39 * *$ & \\
\hline
\end{tabular}

Note. $* * * p<.001, * * p<.01, * p<.05$ 


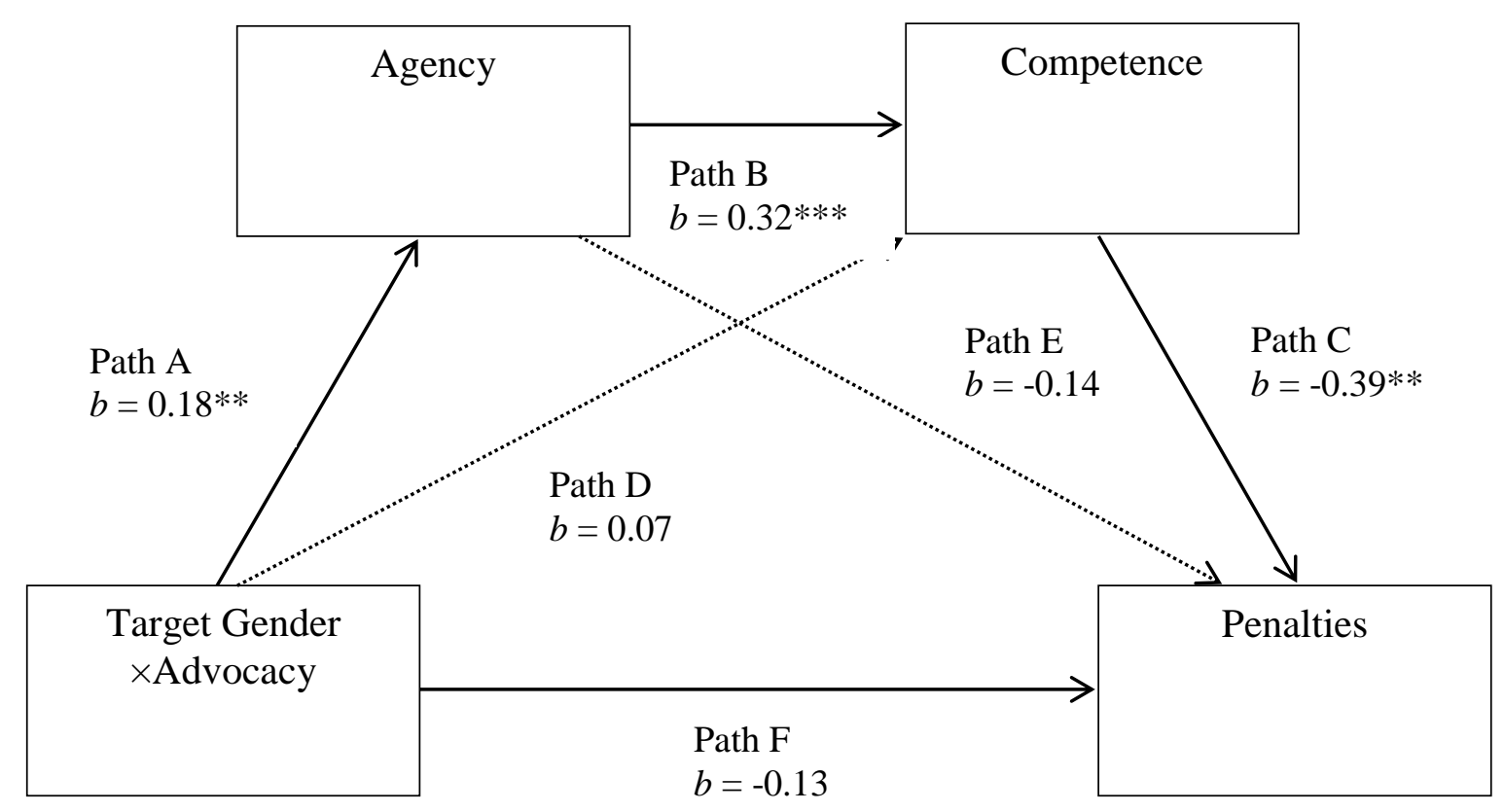

Indirect 1: Bootstrapping: -.02, (CI 95\%) $=[-0.06,-0.01]$

Indirect 2: Bootstrapping: $-.03,(\mathrm{CI} 95 \%)=[-0.08,0.01]$

Indirect 3: Bootstrapping: $-.03,(\mathrm{CI} 95 \%)=[-0.09,0.01]$

Figure 1. Results of the serial multiple mediation testing agency and competence as mediators of the effect of Target Gender $\times$ Advocacy on penalties. $N=149$. Unstandardized regression coefficients are shown. Indirect 1: Target Gender $\times$ Advocacy $\rightarrow$ Agency $\rightarrow$ Competence $\rightarrow$ Penalties. Indirect 2: Target Gender $\times$ Advocacy $\rightarrow$ Agency $\rightarrow$ Penalties. Indirect 3: Target Gender $\times$ Advocacy $\rightarrow$ Competence $\rightarrow$ Penalties. $* p<.05 ; * * p<.01 ; * * * p<.001$ 
1 The materials from Richardson et al. (2001) used a financial company for the vignettes. Backlash research suggests that people judge others based on their gender atypical behavior regardless of the gender-typed nature of their occupation. For example, backlash effects emerge for female leaders whether the job is masculine (computer lab manager), feminine (English professor), or gender neutral (marketing manager; Rudman \& Glick, 2001; Rudman et al., 2012). Backlash has also emerged for atypical men whether they succeed in feminine-typed jobs (Heilman \& Wallen, 2010), compete for masculine-typed jobs (computer lab manager; MossRacusin, Phelan, \& Rudman, 2010); or work for a non-descript company (Rudman \& Mescher, 2013). 